Open Access

\title{
Push-Pull Interface Connections in Steel Frames with Precast Concrete Infill Panels
}

\author{
Johan C.D. Hoenderkamp*, Hubertus H. Snijder and Herm Hofmeyer
}

Department of the Built Environment, Eindhoven University of Technology, P.O. Box 513, VRT 9.18, 5600 MB Eindhoven, The Netherlands

\begin{abstract}
This paper presents experimental and finite element results of investigations into the stiffness and strength of three discrete interface connections between simple steel frames and precast concrete infill panels serving as lateral bracing. The ability of the connections to resist compression and tension allows them to introduce substantial lateral stiffness and strength into so called semi-integral infilled frames.

The discrete connection between a steel frame and a concrete panel consists of two parts: a steel anchor plate welded to multiple anchor bars which are cast in the concrete panel and a gusset plate welded to the frame. For a complete framepanel connection the anchor plate is bolted to the gusset plate thereby allowing composite action of the steel-concrete structure. The bolts in the connection are loaded in shear only.

The connections were employed in full-scale experiments on one-storey, one-bay, hybrid infilled frame structures. Finite element analyses were performed for comparison showing that simulation of the behaviour of the hybrid lateral load resisting structure is possible. The validated finite element models can be used for parametric studies with the goal of developing analytical models as a basis for design rules.
\end{abstract}

Keywords: Infilled frame, interface connection, steel frame, precast concrete panel, experiments, FEM.

\section{INTRODUCTION}

At Eindhoven University of Technology a research program is being carried out on the behaviour of semi-integral infilled steel frames subject to in plane loading, a new type of hybrid lateral load resisting structure. The employment of discretely connected precast concrete panels in simple steel frames is very beneficial and results in a substantial increase in lateral stiffness and strength. Besides the stiffening and strengthening effects of the precast concrete infill panels on the frame structure, economic benefits may be realised in saving costs on materials and labour, especially in high wage countries. Also, a reduction of construction time may be achieved. This saves money, both directly and indirectly, e.g. reduced hindrance to the surroundings of the building site. Reduction of construction time requires measures like the use of prefabricated elements (especially in areas where the precast concrete industry is well developed), time efficient joint construction and smarter construction procedures. Meeting these requirements, an integrated building system is proposed which consists of steel frames with discretely connected precast concrete infill panels, enabling the assembly of tall buildings directly from lorries. The use of precast concrete panels allows them to be placed around service cores or in facades where they can form a lateral load resisting structure contributing significantly to the lateral building stiffness. This structural system is most suitable for the structural design of multi-storey buildings.

*Address correspondence to this author at the Department of the Built Environment, Eindhoven University of Technology, P.O. Box 513, VRT 9.18, 5600 MB Eindhoven, The Netherlands; Tel: +31 40247 3301;

Fax: + 3140245 0328; E-mail: j.c.d.hoenderkamp@tue.nl
When subjected to an in-plane lateral load, the infill in steel framed structures will cause different types of composite behaviour depending on the way it is attached to the steel frame as shown in Fig. (1). Since the early fifties research has been carried out on the structural behaviour of steel frames with masonry infill [1-4] and concrete(like) infill [46]. The infill used to be considered as a non-structural element, thereby conservatively neglecting its significant structural benefits. However, it was shown [5] that ignoring the infill may not be conservative but can cause certain elements in the lower parts of the structure to be overloaded. If connections such as strong bonding or shear connectors at the structural interface between the frame and infill are absent as for example with brick infill, the structure is classified as a non-integral infilled frame, see Fig. (1a). Experimental investigations on non-integral infilled frames under racking load have shown [5-11] that poor interaction between the frame and infill due to the absence of connectors or bonding causes friction at the structural interface. As the infill panel takes a large portion of the lateral load at its loaded corners, the effects of the infill panel are similar to the action of a single diagonal strut bracing the frame as shown in Fig. (2). This analogy is justified by the phenomenon of slip and separation at the interface between the frame and the infill due to the difference in the deformed shapes of the surrounding steel frame and the brick infill. Consequently, frictionslip at the interface becomes a governing factor in a nonintegral infilled frame. The separation in addition to irregularities and unevenness at the structural interface produce considerable variations in strength and stiffness [12].

When a continuous connection is provided by means of strong bonding or shear connectors at the structural interface 


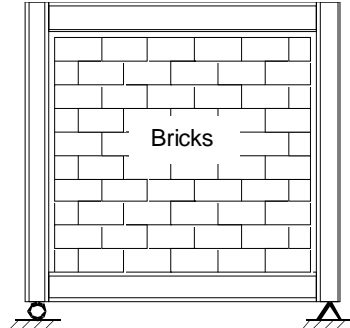

(a) Non -Integral

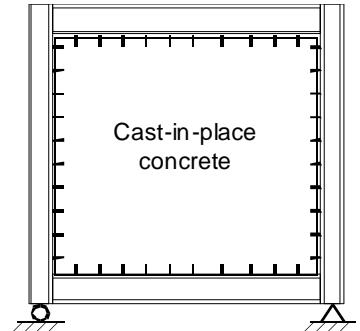

(b) Fully -Integral

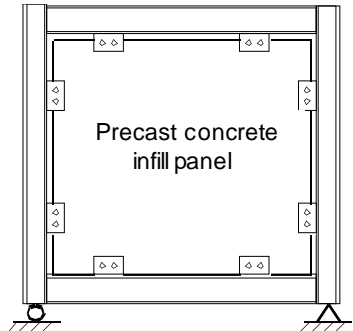

(c) Semi -Integral

Fig. (1). Types of infilled steel frames.
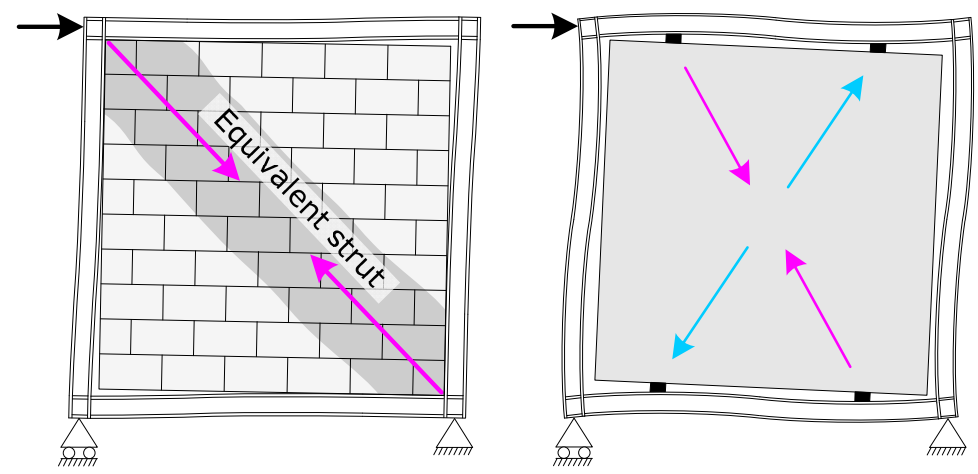

Fig. (2). Infilled frames: brick infill and a precast concrete panel with beam connections.

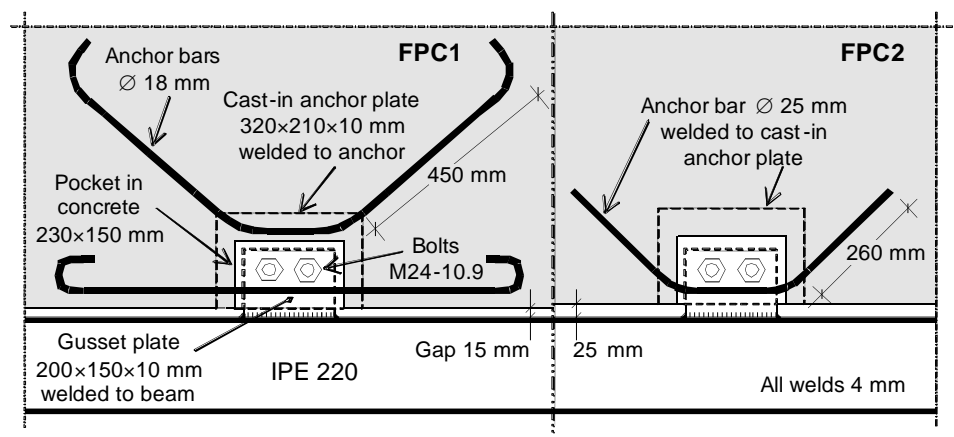

Fig. (3). Frame-panel connections.

between frame and infill panel as shown in Fig. (1b), the separation at the interface will be restricted and the performance of infilled frames is improved. Such frames are classified as fully-integral infilled frames. Friction-slip, which is dependent on normal stress, will not play an important role in fully-integral infilled frames. In addition, the provision of shear connectors overcomes the problem of an initial gap (lack of fit) at the interface. Consequently, fully-integral infilled frames in general have larger lateral stiffness and strength than non-integral infilled frames [13]. They maintain their strength up to large deflections before final collapse of the structure.

When a precast concrete infill panel is connected to a steel frame at discrete locations as shown in Fig. (1c), interaction at the structural interface is neither complete nor absent. A structure comprising a steel frame with an intermittently connected precast concrete panel can be classified as semi-integral. The contribution of precast concrete infill panels to the lateral stiffness and strength of steel frames depends on the quality, quantity and location of the discrete interface connections. The idea of a semi-integral infilled steel frame was considered earlier [14] for an infilled frame with continuous connections along the beams and columns, where a finite shear strength at the infill-frame interface was taken into account over specified distances. Fig. (2) also shows a deformed infilled frame with a panel connected to the beams of the steel frame. The use of discrete frame-topanel connections means that contact only occurs at the frame-panel connections where the forces from the steel frame are introduced into the concrete. This way the infill panel functions as a bracing system with compression and tension forces [15].

As part of the research program, two types of semiintegral infilled steel frames with discretely connected precast concrete infill panels have been developed, tested and numerically investigated: frame-panel-connections that can transfer tension, shear as well as compression [15] and connections that can only transfer compressive forces $[16,17]$. The investigation presented in this paper is concentrated on tension-compression connections. Two frame-panelconnections, FPC1 and FPC2, are shown in Fig (3). They consist of a gusset plate welded to the steel frame and an 
anchor plate with welded anchor bars which are cast in a pocket at the edge of the concrete panel. Two bolts per shear connection attach the gusset plate to the anchor plate.

Preliminary investigations have shown that tensionshear-compression connections on beams are more efficient than on columns and that the lateral stiffness of the structure improves when the connections are located closer to the beam-to-column joints [18]. The later designed connection FPC2 is smaller than FPC1 which allows it to be placed closer to the corners of the steel frame. Both connections have been tested individually and used in full-scale infilled frame tests [15]. The connections are dry and will function immediately after assembly. They are located on the center line of the structural elements thereby keeping eccentricities to a minimum. Due to the gap between the concrete panel and the steel members, friction will not take place.

\section{PUSH-PULL CONNECTION FPC3}

An improvement could be obtained by placing framepanel connections in the four corners of the steel frame at the column-beam junctions. The connections would then not have to be designed to resist shear forces but for tension and compression only. At these locations, as shown in Fig. (4), it is possible to develop a more efficient bracing system with complete X-bracing. To this purpose the push-pull connection type FPC3 was developed.

The corner connection FPC3 as shown in Fig. (5) is a normal force connection designed to be placed very close to the corner beam-to-column joint of the steel frame. It consists of five $16 \mathrm{~mm}$ diameter anchor bars (Feb500) welded to a $15 \mathrm{~mm}$ thick rectangular steel flange plate measuring 389 by $150 \mathrm{~mm}$, perpendicular to the plane of the concrete panel. This plate is welded to a triangular anchor plate which is bolted to a triangular gusset plate using two 10.9 M24 bolts. The gusset plate is welded to the beam.

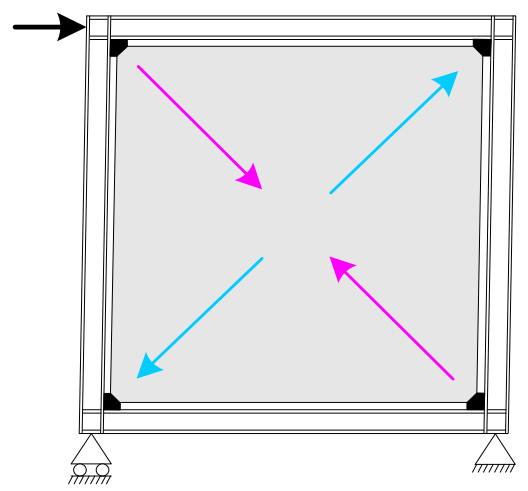

Fig. (4). Infilled frame with corner connections.

Individual tests on these frame-panel-connections FPC3 were performed to establish their load-displacement characteristics. A schematic test-up is shown in Fig. (6) which displays the dimensions of the concrete block. The set-up comprises a single concrete block that is placed on two jacks. The anchor plate is bolted to a steel holding strip replacing the gusset plate, which is connected to a test rig. Vertical displacements were measured on the the anchor plates, the bolts and the concrete panels.

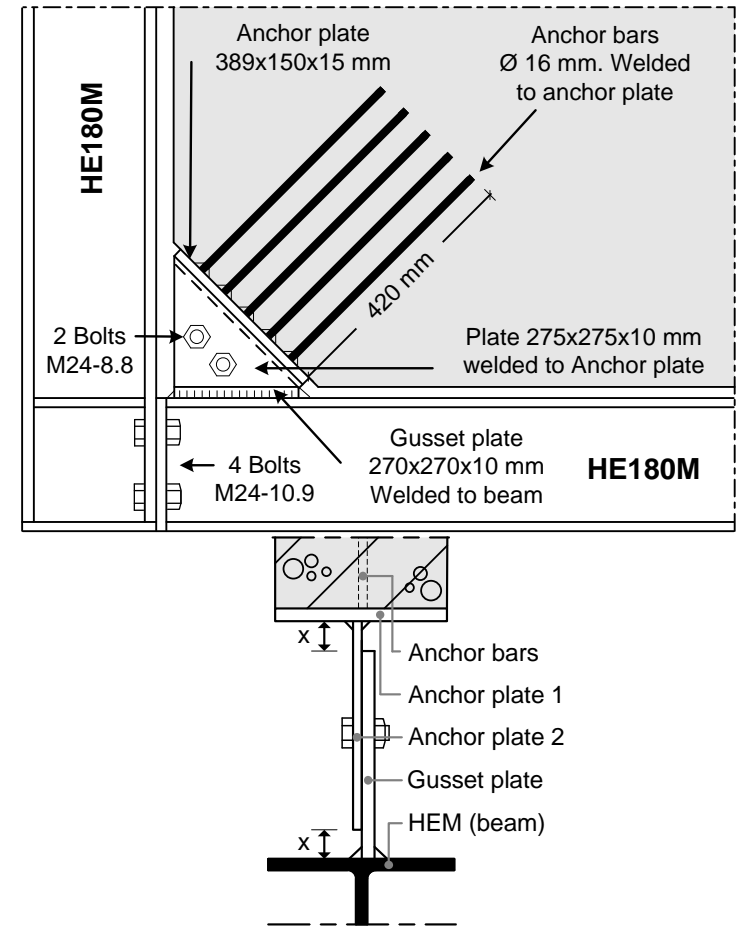

Fig. (5). Frame-panel-connection FPC3.

Four connections of type FPC 3 were tested. Specific data for the materials are given in Table $\mathbf{1}$. For comparative reasons the same information is given for the earlier tested connections FPC1 and FPC2 [15]. The compressive strength of the concrete was obtained from standard cube tests of $150 \times 150 \times 150 \mathrm{~mm}$. The equivalent characteristic cylinder strengths are also given. Anchor plate movement and bolt hole ovalisation in the anchor plates are determining the connection behaviour as shown in Fig. (7). The modes of failure for all tension tests were identical: anchor pull-out.

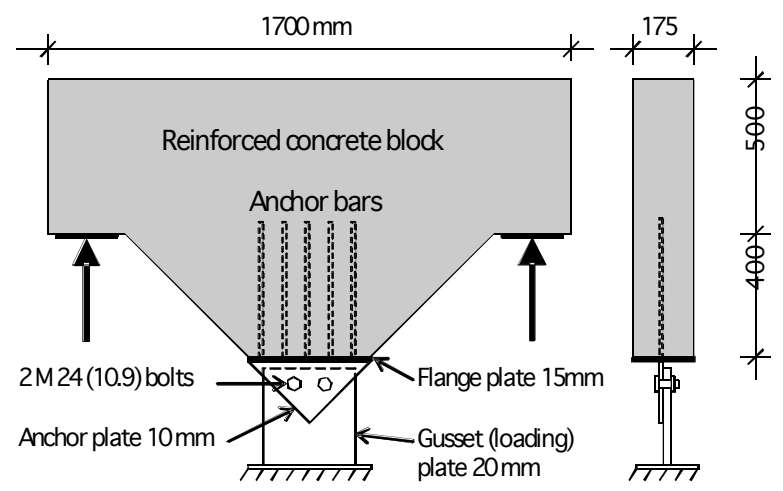

Fig. (6). Test set-up for FPC3.

Load-displacement measurements were done for several characteristic types of behaviour in the connection. This was deemed necessary because the full-scale test to be performed later could have materials with different properties for steel and concrete. Fig. (8). shows four load displacement curves for anchor bar slip in the concrete block. The typical characteristics of the anchor bar behaviour in the concrete are displayed by the modeled pull-out curve in the diagram. 
Table 1. Measured Material Properties of Frame Panel Connections

\begin{tabular}{|l|c|c|c|c|c|c|c|c|c|}
\hline \multirow{2}{*}{} & \multirow{2}{*}{ Bolts } & \multicolumn{2}{|c|}{$\begin{array}{c}\text { Anchor bars } \\
\text { FeB500 }\end{array}$} & \multicolumn{2}{|c|}{ Anchor plates } & \multicolumn{2}{c|}{ Gusset plates } & \multicolumn{2}{c|}{ Concrete panels } \\
\cline { 2 - 9 } & $\mathbf{M} 24$ & $\begin{array}{c}\varnothing \\
\mathbf{m m}\end{array}$ & $\begin{array}{c}\mathbf{f}_{\mathrm{u}} \\
\mathbf{N} / \mathbf{m m}^{2}\end{array}$ & $\begin{array}{c}\mathbf{f}_{\mathbf{y}} \\
\mathbf{N} / \mathbf{m m}^{2}\end{array}$ & $\begin{array}{c}\mathbf{f}_{\mathrm{u}} \\
\mathbf{N} / \mathbf{m m}^{2}\end{array}$ & $\begin{array}{c}\mathbf{f}_{\mathbf{y}} \\
\mathbf{N} / \mathbf{m m}^{2}\end{array}$ & $\begin{array}{c}\mathbf{f}_{\mathrm{u}} \\
\mathbf{N} / \mathbf{m m}^{2}\end{array}$ & $\begin{array}{c}\text { Reinforcing } \\
\text { bars } \\
\mathbf{N} / \mathbf{m m}^{2}\end{array}$ \\
\hline \hline FPC1 & 10.9 & 25 & $500^{(1)}$ & 529 & 579 & 529 & 579 & $\varnothing 10 @ 200$ & $47 / 37^{(2)}$ \\
\hline FPC2 & 10.9 & 18 & $500^{(1)}$ & 247 & 408 & 294 & 432 & $\varnothing 8 @ 150$ & $44 / 34^{(2)}$ \\
\hline FPC3 & 10.9 & 16 & $500^{(1)}$ & 266 & 516 & - & - & $\varnothing 8 @ 100$ & $58 / 45^{(2)}$ \\
\hline
\end{tabular}

${ }^{(1)}$ nominal value, ${ }^{(2)}$ approximate cylinder strength.

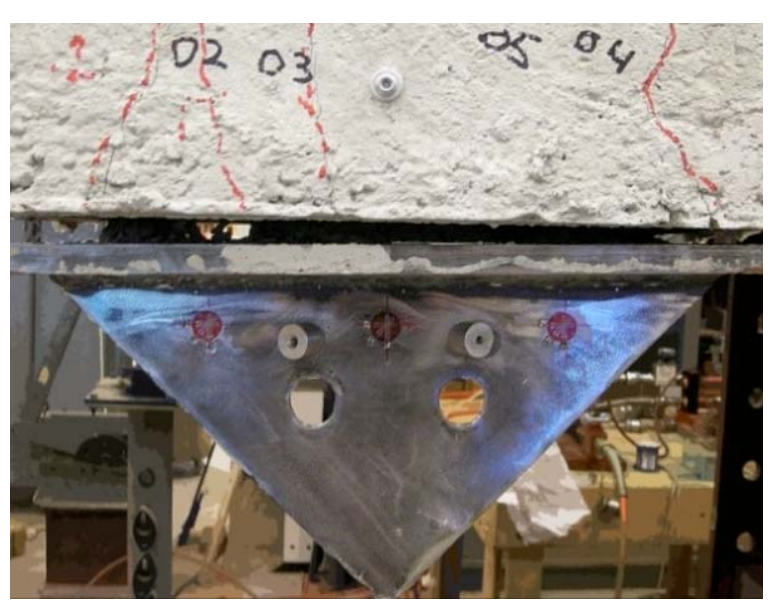

Fig. (7). Test FPC3, anchor pull-out and ovalisation.

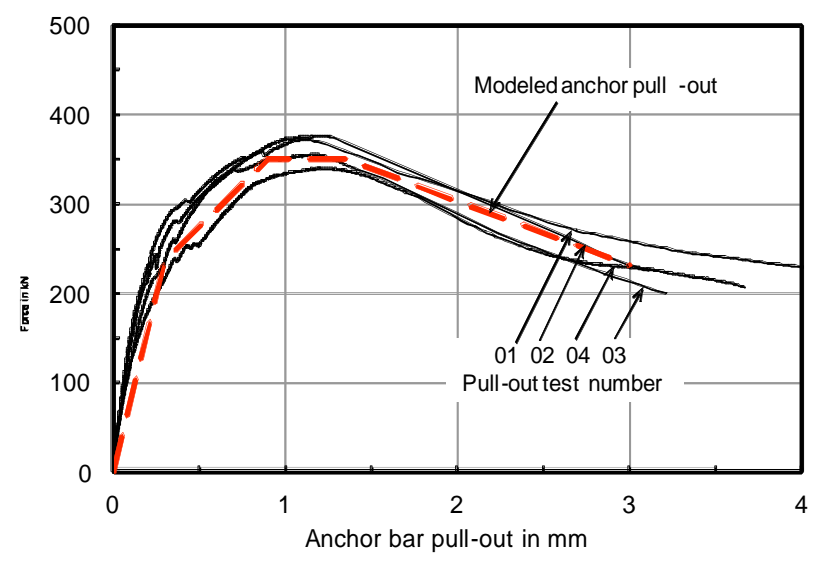

Fig. (8). Force vs. displacement for anchor bar pull-out.

The ovalisation of the bolt holes needed to be measured on both sides of the plates because of rotation of the bolts. This rotation is caused by bending in both the anchor and gusset plates. It occurs in the connections subject to tension as well as in the connections in compression. Successful measurements were only obtained for two tests as shown in Fig. (9). Again, the typical characteristics of bolt hole ovalisation in the anchor plates are displayed by a modeled ovalisation curve.

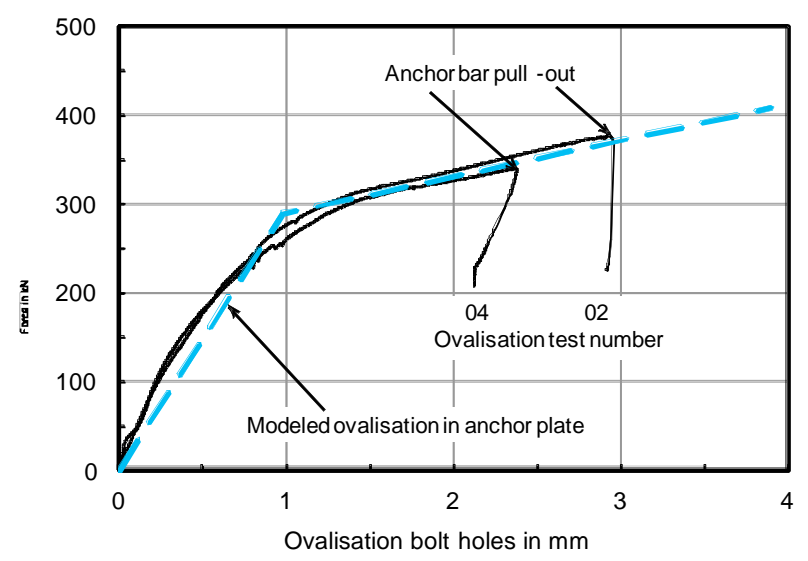

Fig. (9). Force vs. displacement for bolt hole ovalisation in anchor plate.

The rotation of the bolts in the connection displayed in Fig. (10) has also been measured during the tests. As for the ovalisation measurements it resulted in only two sets of useful data as shown in Fig. (11). The curve "Modeled bolt rotation" is taken to represent its typical characteristics.

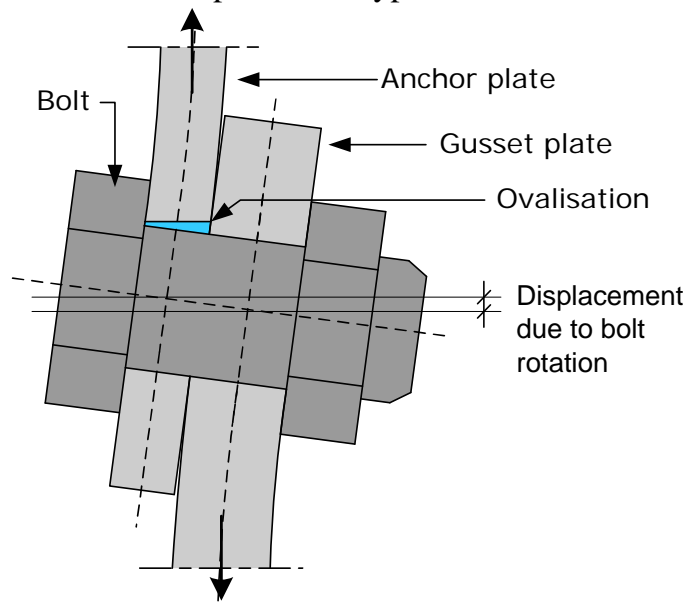

Fig. (10). Bolt rotation; displacement due to anchor plate and gusset plate bending.

The modeled curves represent three characteristic modes of behaviour in the connection. They allow the strength and stiffness of similar connections in full-scale infilled frame tests, but with different material properties, to be determined 
for analysis of this frame. This procedure will be discussed in the proceeding sections.

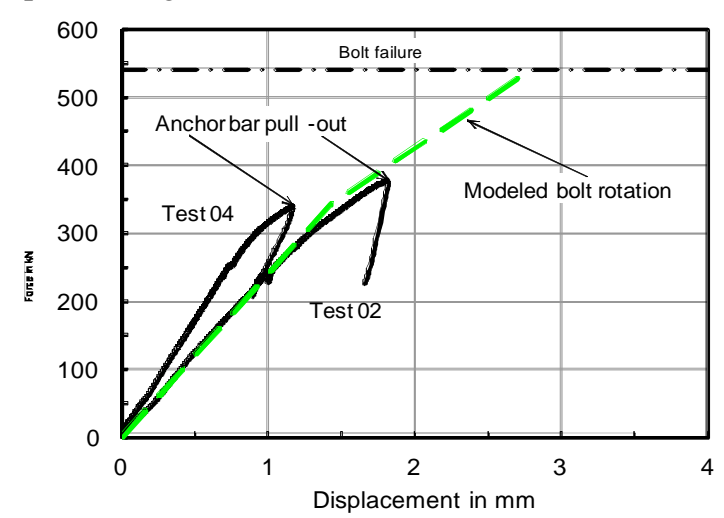

Fig. (11). Force vs. displacement for bolt rotation due to bending of connection plates.

\section{FULL SCALE INFILLED FRAME TEST WITH FPC3}

A full scale infilled frame test with FPC3 connections was carried out in a specially designed test rig for infilled frames as shown in Fig (12). The rig consists of a vertical and a diagonal loop assembled from HE300B sections. At the top left corner of the test rig a hydraulic jack is mounted, with a capacity of $2 \mathrm{MN}$ and a stroke of $200 \mathrm{~mm}$. At the lower left corner of the test rig the test specimen will be supported only in vertical direction to simulate a roller support. Four steel M30 threaded rods are used to transfer vertical loads to the vertical loop of the test rig and they permit rotation and horizontal translation of the test specimen. At the lower right corner of the test rig, the specimen is supported in a steel block or saddle. This support acts like a hinged connection and only allows the test specimen to rotate in its plane. Lateral and vertical translations are restricted. The test specimen is loaded in one direction only.

The steel frame of the infilled structure to be tested consists of four HE180M steel sections (S235), two beams and two columns. The beams are connected to the columns with four M24 10.9 bolts. The bolts are torque controlled tightened up to a specified torque of $400 \mathrm{Nm}$, to obtain an identical rotational stiffness at each beam column connection. Triangular gusset plates are welded to the beams near the frame corners for connection to the concrete panel. For the 2760 $\mathrm{mm}$ square infill panel $\mathrm{C} 35 / 45$ concrete was used to cast a slab with a thickness of $200 \mathrm{~mm}$ and a cover of $25 \mathrm{~mm}$. The panel is reinforced with a $\varnothing 8-150$ FeB500 mesh on both sides. Along the panel edges reinforcement hooks $\varnothing 8-150$ FeB500 were placed. The compressive strength of the concrete was determined on the day the full scale experiment was carried out. Table 2 gives the properties of the steel and concrete used in the testing of individual connections FPC3 in addition to the material properties used for the connections and the infill panel in the full scale frame test.

The bare frame was tested to determine its contribution to the stiffness of the infilled frame. The second test was performed on the full scale infilled frame. The bare frame was preloaded up to $20 \mathrm{kN}$, to close initial gaps between the test rig and the specimen. After unloading the test specimen it was loaded again up to $80 \mathrm{kN}$. At this load the bare steel frame only deforms elastically to avoid any damage which could affect the behaviour during the full scale test. After the bare steel frame testing, the concrete panel was connected to the steel frame in a horizontal position at floor level. In this position the weight of the concrete panel does not influence the stresses in the bolts of the frame panel connection. At the

Table 2. Changes in Material Properties

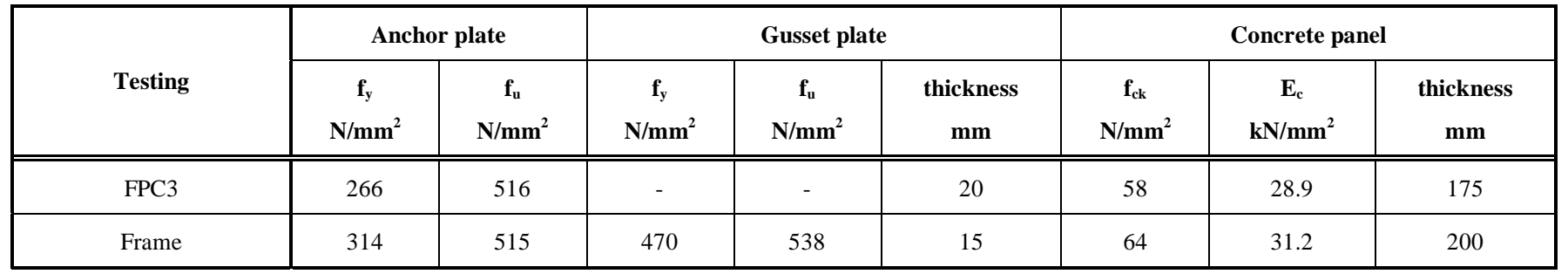
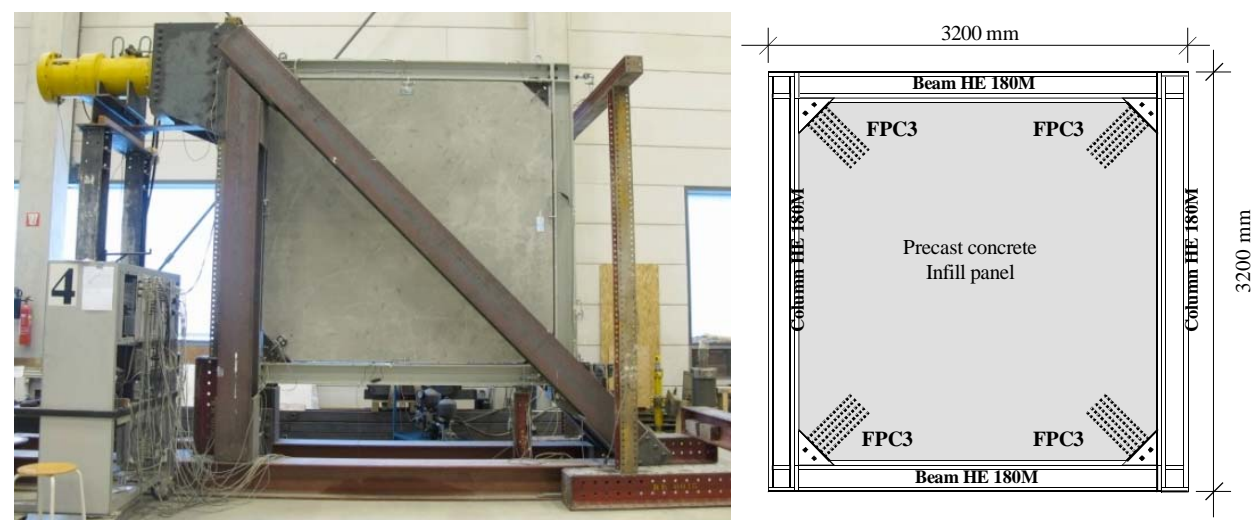

Fig. (12). Full scale test set-up with infilled frame. 
beginning of the infilled frame test, the specimen was subjected to a preload of $50 \mathrm{kN}$. After unloading, the infilled frame was loaded again up to failure under controlled displacement at $1 \mathrm{~mm} / \mathrm{min}$. The load-displacement curves in Fig. (13) show the lateral structural behaviour of four tests. Test A and Test B with frame panel connections FPC1 and FPC2 respectively were performed and presented earlier by the authors [15] and are shown here for comparative purposes. The details of these connections are shown in Fig. (3) and their approximate locations on the beams in Fig. (2).

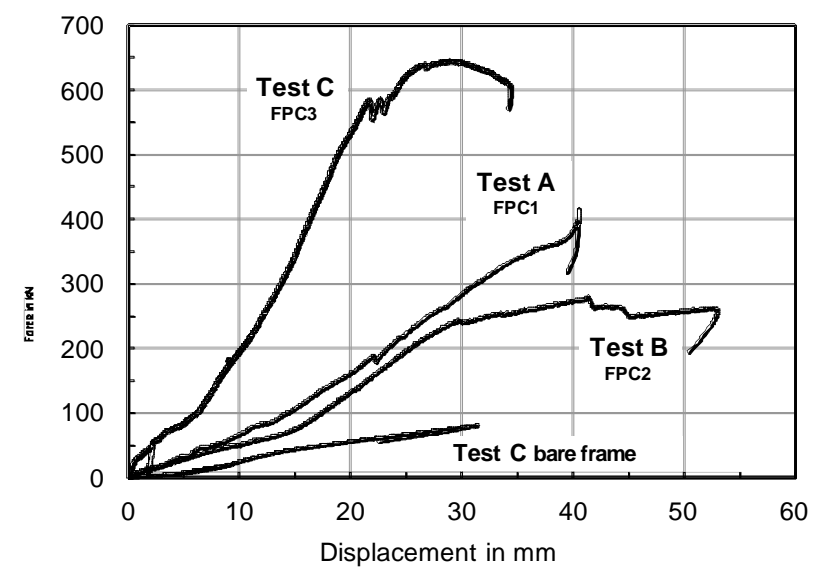

Fig. (13). Force vs. displacement for full scale infilled frame tests.

The results of the present investigation on infilled frames are indicated by Test $\mathrm{C}$ with frame panel connection FPC 3 in addition to a test on its bare frame, i.e. without the precast concrete infill panel. At initial loading of the bare frame the load displacement curve displays a settling-in stage up until about $40 \mathrm{kN}$. It is assumed that initial gaps between the test specimen and test rig are being closed. Thereafter a linear branch can be observed which represents the lateral stiffness of the bare frame: $2.3 \mathrm{kN} / \mathrm{mm}$. This represents the contribution of the bare frame to the overall horizontal stiffness of the infilled frame.

The settling-in stage of the infilled frame structure until $\pm 100 \mathrm{kN}$ is a combination of closing the initial gap between test specimen and test rig, and non-simultaneous getting into contact of the 8 FPC3 bolts with the gusset and anchor plates. The behaviour of specimen $\mathrm{C}$ can be considered linear to $584 \mathrm{kN}$ with an initial stiffness of $34.8 \mathrm{kN} / \mathrm{mm}$. At this load the first crack in the tension diagonal of the concrete panel occurs near the ends of the $420 \mathrm{~mm}$ long anchor bars of the upper 'tension connection'. After a load drop of $22 \mathrm{kN}$ the lateral load again increases to $585 \mathrm{kN}$ when a crack at the opposite corner in the tension diagonal occurs. This crack is also located at the end of the anchor bars and caused a load drop of $21 \mathrm{kN}$. From this point on the lateral load increases to $644 \mathrm{kN}$ with a deflection of $28.9 \mathrm{~mm}$. After reaching the ultimate strength of the infilled frame, large out of plane deformations were observed in the anchor and the gusset plates of the frame panel connection in the lower compression corner, see Fig. (14). This resulted in a decreasing load and increasing lateral displacements of the infilled frame structure as clearly indicated by the Test $\mathrm{C}$ curve in Fig. (13).

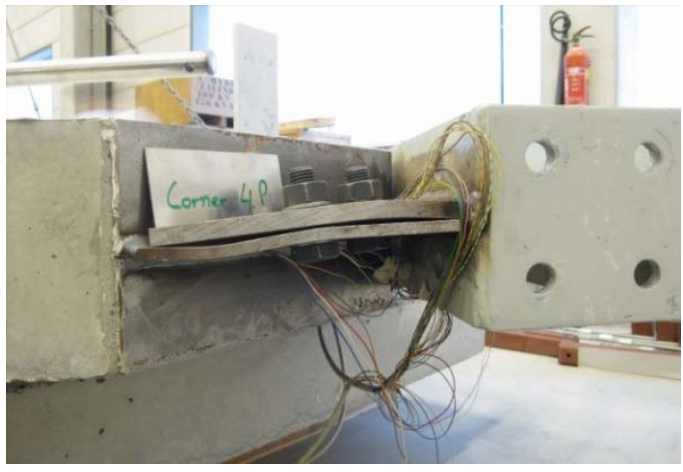

Fig. (14). Out-of-plane deformations in anchor and gusset plates of FPC3.

Salient data obtained from the three infilled frame tests are given in Table 3. It is clearly shown that placing frame panel connections in the corners of the frame yields significantly improved strength and stiffness over infilled frames with connections to the beams.

Table 3. Comparison of Steel Frames with Precast Concrete infill Panels

\begin{tabular}{|c|c|c|c|}
\hline & $\begin{array}{c}\text { Yielding level } \\
\mathbf{k N}\end{array}$ & $\begin{array}{c}\text { Ultimate } \\
\text { strength } \\
\mathbf{k N}\end{array}$ & $\begin{array}{c}\text { Lateral stiffness } \\
\mathbf{k N} / \mathbf{m m}\end{array}$ \\
\hline \hline Test A & 345 & - & 15.9 \\
\hline Test B & 241 & 276 & 12.5 \\
\hline Test C & 584 & 644 & 34.8 \\
\hline
\end{tabular}

\section{FINITE ELEMENT ANALYSIS OF FULL SCALE INFILLED FRAME}

A simple finite element model as shown in Fig. (15) was developed in the finite element program ANSYS 12.0.1 [19] for simulating the racking shear behaviour of the full-scale infilled frame test. The set up of the finite element model is presented in the following order: steel frame and precast concrete panel, frame-panel connection, and infilled frame. For these three parts, the applied elements, element geometry, and material characteristics are discussed.

\subsection{Steel Frame and Precast Concrete Infill Panel}

BEAM3 elements are used to model the beams and columns of the steel frame. This two node uni-axial element has tension, compression and bending capabilities. A node has three degrees of freedom: translation in the nodal $x$ and $y$ directions and rotation about the nodal $z$-axis. The bolted connections between the beams and columns of the steel frame are replaced by torsional springs in the finite element analysis as shown in Fig. (15). COMBIN39 elements are used to model these springs. The applied torsional spring is a purely rotational element with three degrees of freedom at each node, however in the finite element model only the rotations about the nodal $z$-axis are admitted. The relative translation in $x$ and $y$ directions will be restricted by constraints. 


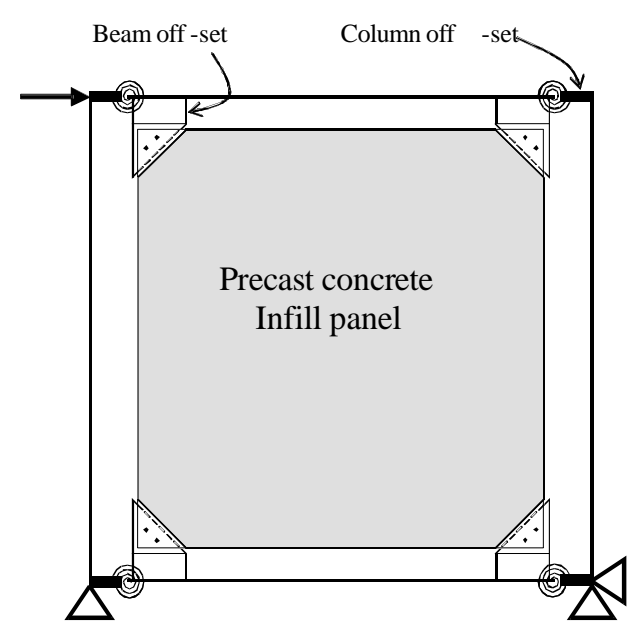

Fig. (15). Simplified finite element model of infilled frame.

For the beams and columns nominal values of HE180M sections are used: sectional area $A=11325 \mathrm{~mm}^{2}$, sectional height $h=200 \mathrm{~mm}$ and moment of inertia $I_{y}=74830000$ $\mathrm{mm}^{4}$. The beams and columns are divided into thirty beam elements each. The rotational spring representing the bolted connection between the columns and beams is located at the end of a rigid offset that is connected to the column end at the neutral axis of the beam. The material property that is used for the steel sections is Young's modulus $E_{s}=210000$ $\mathrm{N} / \mathrm{mm}^{2}$. The rotational spring characteristics $\left(C_{T}\right)$ that represent the bolted connection between the beams and columns of the bare steel frame can be indirectly obtained from the force-deflection curve for "Test C bare frame" shown in Fig. (13). They are modeled with a bi-linear moment-rotation curve: the initial stiffness up to a bending moment of 28 $\mathrm{kNm}$ is $19640 \mathrm{kNm} / \mathrm{rad}$, thereafter the stiffness is 8909 $\mathrm{kNm} / \mathrm{rad}$.

PLANE183 elements are used to model the precast concrete panel. This higher order $2 \mathrm{D}$ plane stress element has 8 nodes for quadratic shaped elements and 6 nodes for triangular shaped elements. The element has two degrees of freedom at each node. These are translation in the nodal $x$ and $y$ directions. Quadratic and triangular elements are used to model the geometry of the rectangular infill panel. The triangular elements shown in Fig. (16). are applied where the concrete panel connects to the anchor plate to accommodate the transition between the mesh of the concrete panel and the mesh of anchor plate. The material properties of the concrete have been experimentally determined, $E_{c}$ is $32127 \mathrm{~N} / \mathrm{mm}^{2}$ and the Poisson's ratio is taken as 0.2.

\subsection{Frame-Panel Connection}

The offset, gusset, and anchor plates of FPC3 shown in Fig. (16) are modeled with PLANE183 plane stress elements. They have a Young's modulus of $210000 \mathrm{~N} / \mathrm{mm}^{2}$ and their Poisson's ratio is 0.3 . Triangular elements are used to model the gusset plate and anchor plate of the frame panel connection. The gusset plate is connected to an offset, which represents half the depth of the beam, and is modeled with quadric elements. The thickness of the gusset plate and offset area is $15 \mathrm{~mm}$. All other dimensions of the frame panel connection are shown in Fig. (5). The anchor plate is directly connected to the concrete panel to prevent deformations be- tween the two components, i.e. movement of the anchor bars is modeled by the springs. The flange plate could thus be omitted in the analysis.

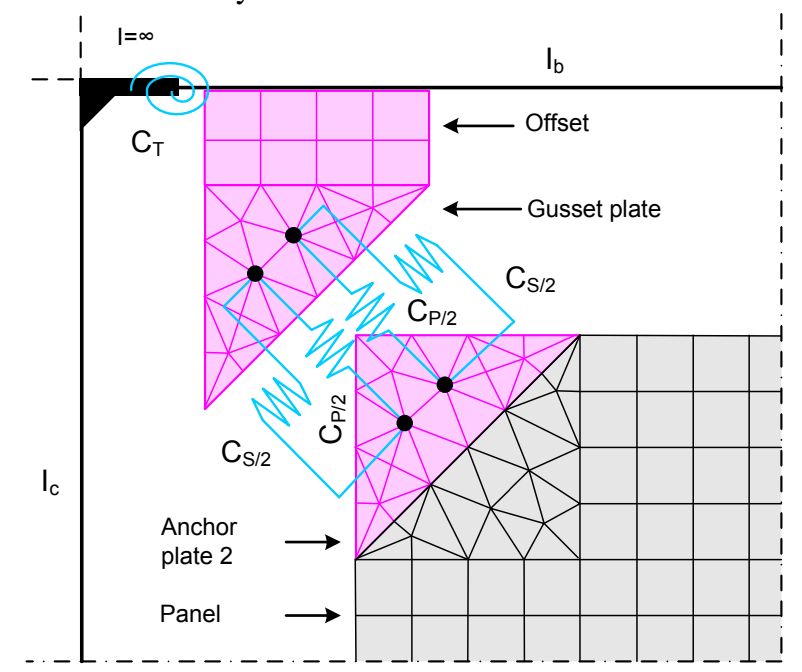

Fig. (16). Finite element model of FPC3.

COMBIN39 spring elements are used to model 4 translational springs that represent shear action $C_{s}$ in Fig. (16) and normal action $C_{p}$ in Fig. (16). Shear and normal action together are used to model three specific modes of behavior in the connection: anchor slip/pull-out, ovalisation of the bolt holes, and rotation of the bolts due to asymmetric loading in the connection. The longitudinal spring stiffness $C_{p}$, represents bolt hole ovalisation, slip of the anchor bars and bolt rotation. In order to prevent the concrete panel from rigid body rotation orthogonal springs are inserted. These springs with a combined stiffness $C_{S}$ only represent bolt hole ovalisation and bolt rotation since slip of the anchor bars does not occur in this direction. The experiment based load displacement curves for anchor bar pull-out, bolt hole ovalisation and bolt rotation are shown in Figs. $(\mathbf{8}, \mathbf{9})$ and $(\mathbf{1 1})$ respectively. They were obtained for material properties given in Table $\mathbf{1 .}$

As shown in Table 2 , the properties of steel and concrete used in the full-scale infilled frame test were not the same as used in the connection tests. It is therefore necessary to adjust the experiment based load displacement curves of the three specific modes of behaviour of the connection in order to obtain a correct finite element analysis of the infilled frame.

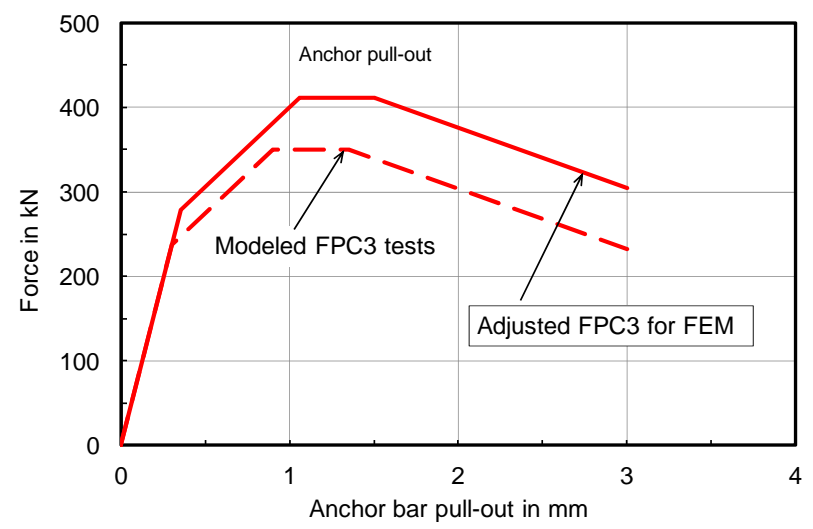

Fig. (17). Adjustment of force-displacement curve for anchor bar pull-out. 


\subsubsection{Anchor Bar Pull-Out}

The modeled anchor pull-out curve in Fig. (8) is shown again in Fig. (17) by the dashed line. The adaptation of the load displacement curve can be obtained by applying an earlier proposed equation [20] that relates the anchor pull-out to the concrete compressive strength, the cover of the anchor bolts and their spacing.

$\frac{\ell_{\mathrm{d}}}{d_{\mathrm{b}}}=\frac{1.85 f_{\mathrm{y}}}{\left(\frac{c+b_{\mathrm{e}} / 3}{d_{\mathrm{b}}}\right) \sqrt{f_{\mathrm{c}}^{\prime}}}$

where $\ell_{\mathrm{d}}$ and $d_{\mathrm{b}}$ are the length and the diameter of the anchor bar respectively, $c$ is the concrete cover, $b_{\mathrm{e}}$ is the anchor bar spacing, $f_{\mathrm{y}}$ is the yield strength of the bar and $f^{\prime}$ c is the concrete compressive strength. For all connection tests and the infilled frame test the spacing, diameter, and length of the anchor bars remained unchanged. It is suggested that the yield strength of the anchor bar, represented by $f_{\mathrm{y}}$ in equation (1), be replaced by the actual stress $F / A$, i.e. the tensile force $F$ in anchor bar divided by its sectional area $A$. With the known changes in concrete cover, the equation can be rewritten as follows:

$\left\{\frac{\frac{F}{A}}{\left(\frac{c+b_{\mathrm{e}} / 3}{d_{\mathrm{b}}}\right) \sqrt{f_{\mathrm{c}}^{\prime}}}\right\}_{\text {FPC3 }}=\left\{\frac{\frac{F}{A}}{\left(\frac{c+b_{\mathrm{e}} / 3}{d_{\mathrm{b}}}\right) \sqrt{f_{\mathrm{c}}^{\prime}}}\right\}_{\text {Infilled Frame }} \ldots$

Substituting and using the known pull-out load from the connection tests will yield an adjusted anchor bar capacity.

$$
\left\{\frac{\frac{350}{1004}}{\left(\frac{80+65 / 3}{16}\right) \sqrt{58}}\right\}_{\text {FPC3 }}=\left\{\frac{\frac{F}{1004}}{\left(\frac{92+65 / 3}{16}\right) \sqrt{64}}\right\}_{\text {Infilled Frame }} \ldots
$$

The adjusted pull-out load of the anchor bars in a single connection is $411 \mathrm{kN}$. This is an increase of $17 \%$ compared to the maximum force of the bar in the connection tests at $350 \mathrm{kN}$. It is suggested that the forces of the anchor bar slip curve be increased with 17\% leaving the slopes of the curve unchanged, see Fig. (17). It is assumed that the change in the modulus of elasticity has little influence on the pull-out characteristics and is therefore ignored.

\subsubsection{Bolt Hole Ovalisation}

Fig. (18) displays a bi-linear relation "Ovalisation in anchor plate (a)" as a dashed line. This modeled curve is derived from the force-displacement curve for bolt hole ovalisation shown in Fig. (9). The steel used for the anchor plates in the full scale tests was of a higher grade compared to the material used in the connection tests, Table 2. This requires an alteration to the force-displacement curve. The ratio between the yield stresses of the anchor plates used for the individual FPC3 testing and for the connections used in the infilled frame test is used to adjust the yielding level of the bolt hole ovalisation as follows:

$F_{\mathrm{AP}}=\frac{f_{\mathrm{y}}}{f_{\mathrm{y} ; \mathrm{FPC} 3}} F_{\mathrm{FPC} 3}=\frac{314}{266} \times 290=342 \mathrm{kN}$ where $F_{\mathrm{FPC} 3}$ is the yield level of ovalisation for the "Modeled FPC3 tests" shown in Fig. (18) and $F_{\mathrm{AP}}$ is the adjusted yield level of ovalisation in the anchor plate. It is assumed that the initial elastic stiffness and subsequent plastic stiffness remain unchanged. This leads to the curve "Adjusted ovalisation in anchor plate (b)". Due to anchor pullout the ultimate ovalisation load at rupture could not be obtained. Instead, the ultimate load is now set at the theoretical shear resistance of the two M10.9 bolts in the connection (bolt failure):

$F_{\mathrm{v} ; \mathrm{Rd}}=2 \alpha_{\mathrm{v}} f_{\mathrm{ub}} A=2 \times 0.6 \times 1000 \times 452 \times 10^{-3}=540 \mathrm{kN} \cdots$

In which $\alpha_{\mathrm{v}}$ is a factor depending on the location of the shear plane $\left(\alpha_{\mathrm{v}}=0.6\right.$ for shear plane passing through the unthreaded portion of the bolt), $f_{\mathrm{ub}}$ is the ultimate strength of the bolt material and $A$ is the gross cross section of the bolt if the shear plane passes through the unthreaded portion of the bolt. This load is beyond the actual loading of the connection in the full scale test and is not expected to be reached in the finite element analysis.

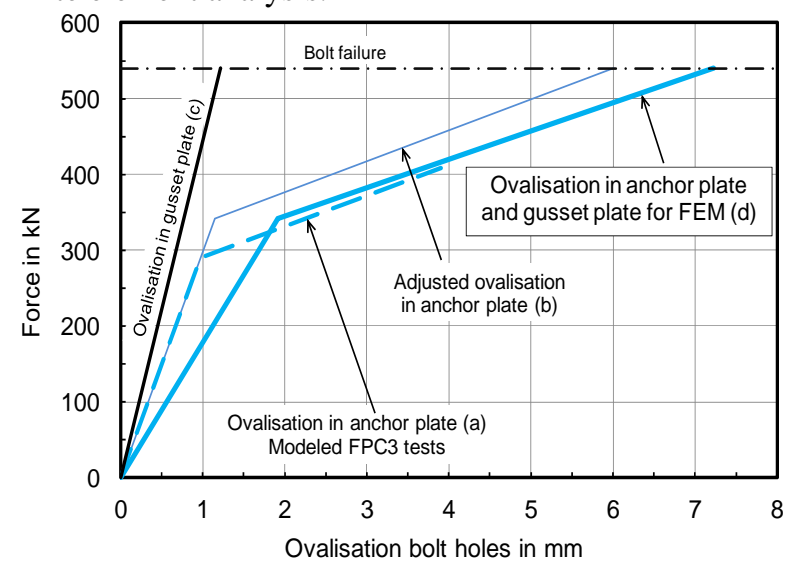

Fig. (18). Adjustment of force-displacement curve for ovalisation of bolt holes in connection plates.

The deformation characteristics of ovalisation in the 20 $\mathrm{mm}$ thick loading (gusset) plate used in the FPC3 tests are unknown. It is therefore suggested that the force-ovalisation behaviour of the $15 \mathrm{~mm}$ thick gusset plates used in the frame analysis be derived from the $10 \mathrm{~mm}$ thick anchor plate by increasing its initial stiffness by $33 \%$. It is taken that the yielding level of the gusset plate $F_{\mathrm{GP}}$ changes proportionally to the yielding level of anchor plate $F_{\mathrm{AP}}$ according to their yield stress ratio:

$F_{\mathrm{GP}}=\frac{f_{\mathrm{y} ; \mathrm{GP}}}{f_{\mathrm{y} ; \mathrm{AP}}} F_{\mathrm{AP}}=\frac{470}{314} \times 342=512 \mathrm{kN} \ldots$

The plastic behaviour of the ovalisation in the gusset plate is omitted here since the elastic strength of $512 \mathrm{kN}$ is about 5\% below the theoretical shear resistance of the bolts, at $540 \mathrm{kN}$. This allows the relationship "Ovalisation in gusset plate (c)" to be set up as shown in Fig. (18). The curve "Ovalisation in anchor plate and gusset plate for FEM (d)" can now quite easily be obtained by adding curves (b) and (c).

\subsubsection{Bolt Rotation}

Due to asymmetric forces in the frame panel connection the gusset plate and anchor plate will bend, which leads to 
rotation of the bolts and causes a displacement in the frame panel connection as shown in Fig. (10). The "Modeled bolt rotation" curve shown in Fig. (11) for a $10 \mathrm{~mm}$ thick anchor plate and a $20 \mathrm{~mm}$ thick loading (gusset) plate is presented again in Fig. (19) as dashed line "Modeled FPC3 tests". As the thickness of the gusset plate used in the full scale test is only $15 \mathrm{~mm}$, the force displacement behaviour of the bolt rotation needs to be altered. The following procedure is suggested. The bending stiffness ratio of the plates used in the full scale test, $10 \mathrm{~mm}+15 \mathrm{~mm}$ thick, and the plates of the connection test, $10 \mathrm{~mm}+20 \mathrm{~mm}$ thick, can simply be expressed as a ratio of the sum of their second moments of area:

$$
\frac{K_{\text {Infilled Frame }}}{K_{\mathrm{FPC} 3}}=\frac{10^{3}+15^{3}}{10^{3}+20^{3}}=0.486
$$

It is suggested that the force-displacement curve for bolt rotation curve be adjusted accordingly. This leads to the FEM curve shown in Fig. (19). There are two additional phenomena that need to be addressed briefly but are considered to have a minor influence on the bolt rotation characteristics and have been ignored in further analyses. The thinner gusset plate used in the full scale frame test creates a smaller moment arm between the neutral lines of the connection plates, see Fig. (10). This causes smaller bending moments and smaller bolt rotations. Additionally, the yielding levels in the two connection tests for bolt rotation were difficult to obtain as anchor pull-out occurred earlier than expected as shown in Fig. (11). For simplicity they have been set at the adjusted yield level value of ovalisation as shown in Fig. (18) at $342 \mathrm{kN}$.

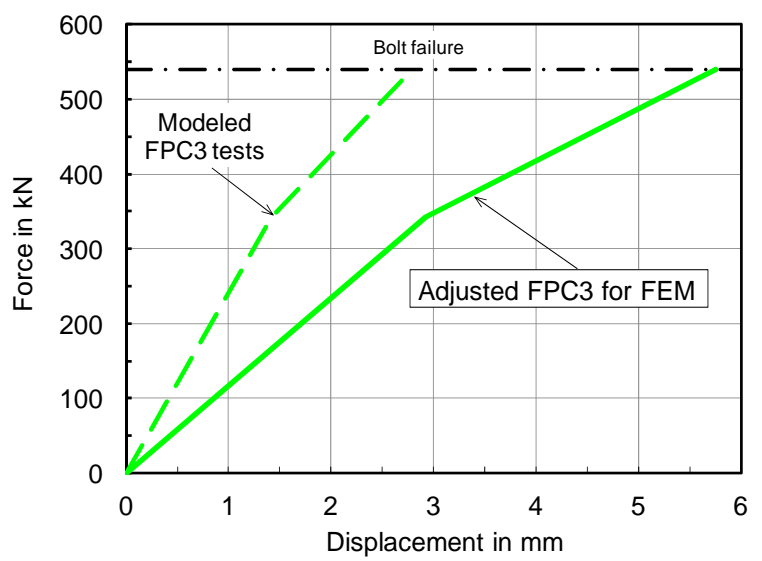

Fig. (19). Adjustment of force-displacement curve for bolt rotation.

\subsubsection{Adjusted Force Versus Displacement Curves for FPC3}

The separate force-displacement characteristics of anchor bar slip, bolt hole ovalisation, and bolt rotation are shown together in the diagram of Fig. (20). They are combined to form a spring stiffness for tension, $C_{\mathrm{P}}$. The spring stiffness for compression, $C_{\mathrm{S}}$ consists of a combination of bolt hole ovalisation and bolt rotation since anchor bar slip does not occur under compression. As mentioned earlier, the compression spring is also used to prevent the concrete panel from rigid body rotation, see Fig. (16).

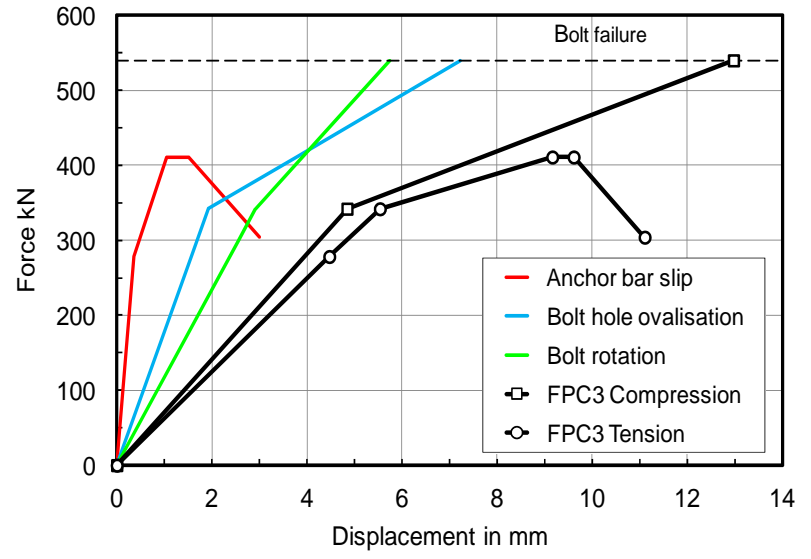

Fig. (20). Adjusted partial and total force-displacement curves for FPC3.

The two spring characteristics for tension and compression can be combined into one overall spring characteristic for use in the finite element model. The decreasing stiffness of the spring characteristic after anchor bar pull-out is adjusted to avoid solution errors during the finite element analysis, i.e. the negative slope of the multi-linear curve is to be reduced. Table $\mathbf{4}$ shows the structural properties of FPC3 together with the characteristics of earlier investigated connections FPC1 and FPC2 to illustrate the developments in frame to panel connections.

\subsection{Full Infilled Frame Analysis}

The lateral load of the experimental test will be represented by a prescribed horizontal displacement in the finite element analysis. The solution procedure is displacement controlled, since the load displacement tangent is expected to become negative, see Fig. (13). It should be noted that the settling-in phase observed in the full scale test is not included in the numerical analysis.

Geometric nonlinearity is taken into account. Material non-linearity for the steel and concrete used is not taken into account. However, the nonlinear springs, for which the behaviour is shown in Fig. (20), include the effects of e.g. ovalisation, which means that plasticity is described implicitly.

Fig. (21) shows the load-deflection curve of the full-scale infilled frame obtained from the finite element analysis compared with the zero corrected results of Test C. This correction was obtained by performing a regression analysis on the linear part of the load-deflection curve after the settling-in phase. The linear curve was projected on the abscissa. Then the adjusted curve was translated to the origin.

Plastic ovalisation of the bolt holes first occurred at the compression corners at $538 \mathrm{kN}$ shortly followed by plastic ovalisation of the bolt holes at tension corners at $586 \mathrm{kN}$. This caused a major reduction of the lateral stiffness. The yielding level is taken to occur at the intersection of the elastic and plastic gradients which is at $555 \mathrm{kN}$. This compares reasonably well to the yielding level of $584 \mathrm{kN}$ for Test $\mathrm{C}$, a $5 \%$ underestimate. The elastic stiffness obtained from the finite element simulation at $34.0 \mathrm{kN} / \mathrm{mm}$ underestimates the experimentally obtained value of $34.8 \mathrm{kN} / \mathrm{mm}$ by only $2 \%$. 
Table 4. Adjusted Structural Properties of FPC3 and Earlier Investigated Connections [15]

\begin{tabular}{|c|c|c|c|c|c|c|}
\hline \multirow{2}{*}{ FPC } & \multicolumn{2}{|c|}{ Shear } & \multicolumn{2}{c|}{ Tension } & \multicolumn{2}{c|}{ Compression } \\
\cline { 2 - 6 } & $\begin{array}{c}\text { Stiffness } \\
\mathrm{K}_{\mathrm{s}}, \mathrm{kN} / \mathrm{mm}\end{array}$ & $\begin{array}{c}\text { Strength }^{(1)} \\
\mathrm{f}_{\mathrm{s} ; \mathrm{u}}, \mathrm{kN}\end{array}$ & $\begin{array}{c}\text { Stiffness } \\
\mathrm{K}_{\mathrm{p}}, \mathrm{kN} / \mathrm{mm}\end{array}$ & $\begin{array}{r}\text { Strength }^{(1)} \\
\mathrm{f}_{\mathrm{p}, \mathrm{u}}, \mathrm{kN}\end{array}$ & $\begin{array}{c}\text { Stiffness } \\
\mathrm{K}_{\mathrm{c}}, \mathrm{kN} / \mathrm{mm}\end{array}$ & $\begin{array}{c}\text { Strength }^{(2)} \\
\mathrm{F}_{\mathrm{c} ; \mathrm{u}}, \mathrm{kN}\end{array}$ \\
\hline \hline FPC1 & 76.4 & 453 & 114.2 & 239 & - \\
\hline FPC2 & 56.8 & 350 & 88.8 & 183 & - \\
\hline FPC3 & - & - & $62.3 / 59.9 / 19.0 / 0.0 /-71.6^{(3)}$ & 411 & $70.1 / 24.4^{(3)}$ & 540 \\
\hline
\end{tabular}

${ }^{(1)}$ anchor pull-out, ${ }^{(2)}$ theoretical bolt failure, ${ }^{(3)}$ multi-linear elastic-plastic

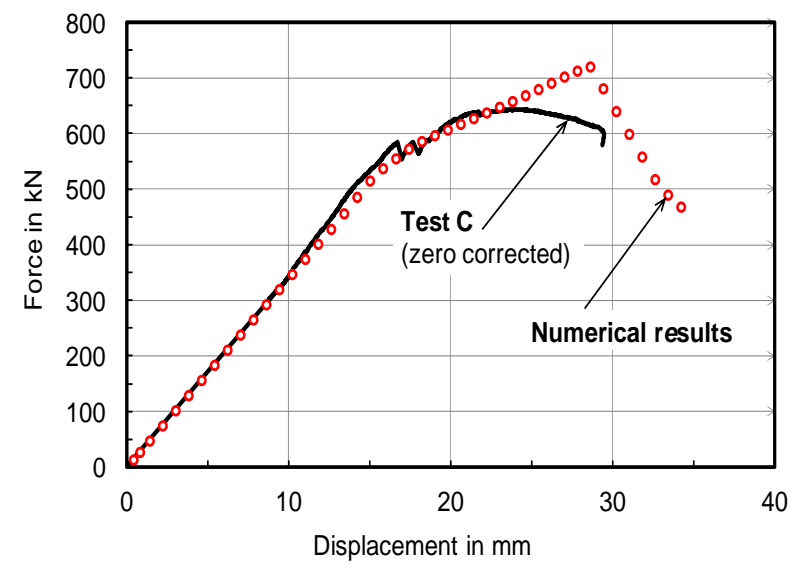

Fig. (21). Force vs. horizontal deflection of infilled frame.

In the simulation the first anchor bar pull-out occurs at the bottom tension connection at $713 \mathrm{kN}$. This is immediately followed by anchor bar failure at that corner at $721 \mathrm{kN}$. As a result the lateral capacity of the infilled frame decreases significantly. The numerically computed ultimate load overestimates the test value by $12 \%$. This is due to the large out of-plane displacement observed during the test at the compression connection plates as shown in Fig. (14). This phenomenon was not modeled in the finite element analysis. The results are given in Table 5 together with earlier published results for tests on infilled frames [15]. It is clearly shown that connection FPC3 performs better than FPC1 and FPC2. The differences obtained in the finite element analyses of the other structures are of the same order as in the present investigation.

\section{DISCUSSION}

A new connection for steel frames with precast concrete infill panels has been designed, tested separately and in a full-scale infilled frame. Its performance in a one-bay-onestory full-scale infilled frame subjected to in-plane horizontal loading was experimentally tested and has been compared to identical frames with similar connections. The use of the new connection FPC3 gives improved strength and stiffness to the standard infilled frame over previously investigated connections. Although the improved frame shows some degree of ductility, it does appear that the ductility of this frame structure is slightly reduced from that obtained with FPC2 connections as shown in Fig. (13).

Mechanical properties of the discrete interface connection were obtained from experiments on individual connections. This allowed characteristic properties for stiffness and strength of the connections to be represented by multi-linear translational springs in finite element analyses of the infilled frames.

\section{CONCLUSIONS}

The experimentally obtained mechanical properties of the infilled frame compare well to numerically derived results. The mechanical properties of this frame were favourably compared to earlier investigated frames with similar

Table 5. Structural Properties of Steel Frames with Precast Concrete infill Panels

\begin{tabular}{|c|c|c|c|c|c|c|c|c|c|}
\hline & \multicolumn{3}{|c|}{$\begin{array}{c}\text { Yielding level } \\
\mathrm{kN}\end{array}$} & \multicolumn{3}{|c|}{$\begin{array}{c}\text { Ultimate strength } \\
\mathrm{kN}\end{array}$} & \multicolumn{3}{|c|}{$\begin{array}{c}\text { Lateral stiffness } \\
\mathrm{kN} / \mathrm{mm}\end{array}$} \\
\hline & 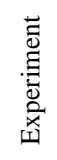 & 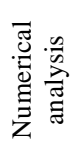 & 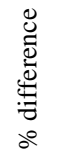 & 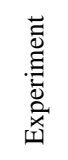 & 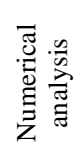 & 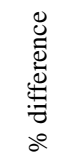 & 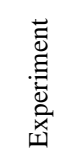 & 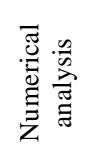 & 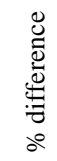 \\
\hline Test A & 345 & 311 & -10 & - & 416 & - & 15.9 & 16.9 & +6 \\
\hline Test B & 241 & 240 & -1 & 276 & 287 & +4 & 12.5 & 14.5 & +16 \\
\hline Test C & 584 & 555 & -5 & 644 & 721 & +12 & 34.8 & 34.0 & -2 \\
\hline
\end{tabular}


connections.

It has been shown that simple finite element models make it possible to systematically investigate the influence of connections on the overall behaviour of steel frames with discretely connected precast concrete infill panels subject to in-plane lateral loading.

The full-scale experimental test shows that a precast concrete panel in a semi-integral infilled steel framed structure with discrete frame-panel connections in the four corners of the frame can significantly improve the lateral stiffness of bare steel frames.

The observed lateral stiffness of the infilled frame structure after the settling-in phase, is roughly 14 times the bare frame stiffness.

The lateral stiffness and ultimate strength of the infilled structure was governed, as intended by design, by the discrete frame-panel connections.

\section{CONFLICT OF INTEREST}

The authors confirm that this article content has no conflicts of interest.

\section{ACKNOWLEDGEMENTS}

The authors would like to thank graduate students R.W.A. Dekker, E.J.H.E. Custers and J. Dekkers for conducting the pull-out tests on the FPC3 connections, and R. Lieven for performing the full scale infilled frame test and preliminary finite element analyses.

\section{REFERENCES}

[1] F.G. Thomas, "The strength of brickwork", Struct. Eng., vol. 31, pp. 35-46,1953.

[2] S.V. Polyakov, "On the interaction between masonry filler walls and enclosing frame when loaded in the plane of the wall", English translation in Earthquake Engineering, Earthquake Engineering Research Institute: San Francisco, pp. 36-42, 1960.

[3] J.R. Benjamin, and H.A. Williams, "The behaviour of one-story reinforced concrete shear walls", J. Struct. Dw. ASCE, vol. 84, no. 4, pp. 1-29, 1958.

[4] M. Holmes, "Steel frames with brickwork and concrete infilling", Proc. Inst. Civil Eng., vol. 19, pp. 473-478, 1961.
[5] B. Stafford Smith, "Lateral stiffness of infilled frames", J. Struct. Div. ASCE, vol. 88, no. 6, pp. 183-199, 1962.

[6] B. Stafford Smith, "Behaviour of square infilled frames", J. Struct. Div. ASCE, vol. 92, no. 1, pp. 381-403, 1966.

[7] B. Stafford Smith, "Methods for predicting the lateral stiffness and strength of multi-storey infilled frames", Build. Sci., vol. 2, pp. 247-257, 1967.

[8] H.K. Barua, and S.K. Mallick, "Behaviour of mortar infilled steel frames under lateral load", Build. Environ., vol. 12, pp. 263-272, 1977.

[9] T.C. Liauw, and K.H. Kwan, "Nonlinear behaviour of non-integral infilled frames", Comput. Struct., vol. 18, no. 3, pp. 551-560, 1984.

[10] T.C. Liauw, and C.Q. Lo, "Multibay infilled frames without shear connectors", J. Am. Concrete Inst., vol. 85, pp. 423-428, 1988.

[11] B.M. Ng'andu, D.R.W. Martens, and A.T. Vermeltfoort, "The contribution of CASIEL infill walls to the shear resistance of steel frames", Heron, vol. 51, no. 4, pp. 201-223, 2006.

[12] J.L. Dawe, and C.K. Seah, "Behaviour of masonry infilled steel frames", J. Can. Soc. Civil Eng., vol. 16, pp. 865-876, 1989.

[13] D.V. Mallick, and R.P. Garg, "Effect of openings on the lateral stiffness of infilled frames", Proc. Inst. Civil Eng., vol. 49, pp. 193210, 1971.

[14] T.C. Liauw, and K.H. Kwan, "Plastic theory of infilled frames with finite interface shear strength", Proc. Inst. Civil Eng., Part2, vol. 75, pp. 707-723, 1983.

[15] J.C.D. Hoenderkamp, H. Hofmeyer, and H.H. Snijder, "Experimental investigation of the shear resistance of steel frames with precast concrete infill panels", Adv Steel Constr., vol. 6, no. 3, pp. 817-830, 2010.

[16] P.A. Teeuwen, C.S. Kleinman, H.H. Snijder, and H. Hofmeyer, "Full-Scale testing of infilled steel frames with precast concrete panels provided with a window opening", Heron, vol. 53, no. 4, pp. 195-224, 2008.

[17] P.A. Teeuwen, C.S. Kleinman, H.H. Snijder, and H. Hofmeyer, "Experimental and numerical investigations into the composite behaviour of steel frames and precast concrete infill panels with window openings", Steel Compos. Struct., vol. 10, no. 1, pp. 1-21, 2010.

[18] R.B. Tang, J.C.D. Hoenderkamp, and H.H. Snijder, "Preliminary Numerical Research on Steel Frames with Precast Reinforced Concrete Infill Panels", In: Proceedings of Structural Stability and Dynamics Conference, Taipei: Taiwan, pp. 575-580, 2000.

[19] Ansys Academic Research 12.0.1, ANSYS, Inc. Southpointe, 275 Technology Drive, Canonsburg, PA 15317, United States.

[20] H. Wang, "An analytical study of bond strength associated with splitting of concrete cover", Eng. Struct., vol. 31, no. 4, pp. 968$975,2009$.

This is an open access article licensed under the terms of the Creative Commons Attribution Non-Commercial License (http://creativecommons.org/licenses/by-nc/3.0/) which permits unrestricted, non-commercial use, distribution and reproduction in any medium, provided the work is properly cited. 